\title{
Electron spin resonance and distribution of some elements in shales
}

\author{
AkIO INAZUMI ${ }^{1}$, TOSHIYUKI ISOBE ${ }^{2}$ and ToShIKaZU TARUTANI ${ }^{2}$ \\ Department of Chemistry, Kagawa University, Takamatsu $760^{1}$ and \\ Department of Chemistry, Kyushu University, Fukuoka $812^{2}$, Japan
}

(Received July 6, 1981: Accepted November 20, 1981)

\begin{abstract}
Five types of ESR signals were observed in shales. The resonance composed of six lines near $g_{\text {eff }}=2$ (type A) is attributed to $\mathrm{Mn}(\mathrm{II})$. Type A resonance is divided into two groups on the basis of its line shape; one exhibits six sharp lines (type A-1), and another shows relatively broad lines (type A-2). The $g_{\text {eff }}=2$ broad resonance (type B) may be attributed to Fe(III). The $g_{\text {eff }}=2$ sharp resonance line (type C) probably results from stable organic free radicals. The $g_{\text {eff }}=4.1$ resonance (type D) can be attributed to high spin $\mathrm{Fe}$ (III) occupying sites of orthorhombic symmetry in clay minerals. Some of the shales show an inclined signal covering a wide magnetic field (type E).

Combination of ESR measurements and leaching experiments made it possible to survey the distribution and states of some elements in shales. In shales which exhibit type A-1 resonance overlapped with type A-2 resonance, $\mathrm{Mn}$ (II) is randomly distributed both in calcite and clay minerals. In shales which exhibit only type A-2 resonance, Mn (II) is associated mainly with clay minerals. Most of the iron in shales is bound to clay minerals. A part of the iron in clay minerals is present as $\mathrm{Fe}$ (III) which shows type D resonance.
\end{abstract}

\section{INTRODUCTION}

Recently, there has been considerable interest in ESR characterization of the structural properties of transition metal ions, especially of $S$-state ions such as $\mathrm{Mn}$ (II) and $\mathrm{Fe}$ (III) ions associated with natural materials such as rockforming minerals (GHOSE and TSANG, 1973) and organic substances in sediments. In particular, a number of ESR studies have been made on clay minerals and related materials (KEMP, 1971, 1972; ANGEL and Hall, 1973; HALl et al., 1974; Meads and Malden, 1975; ANGel and VINCENT, 1978). However, ESR apectra of the shale, which is composed of some minerals including clay minerals, have not been examined yet.

The present study was undertaken to elucidate the ESR features of shales and to survey the distribution of elements in them. For this purpose, ESR measurements were carried out on several shales as well as on some minerals prior to and after chemical and thermal treat- ments. Furthermore, leaching experiments were performed on these shales, and correlations among the elements leached from the samples were examined. Distribution of manganese, iron and magnesium in minerals occurring in shales was studied by combining ESR spectroscopy and leaching experiments.

\section{MATERIALS}

The following is a brief description of rock and mineral samples used in the present study. Sh-1 (No. 396): black shale from the Paleozoic strata in Kake-cho, Hiroshima Prefecture, Southwest Japan. This shale contains only illite as clay mineral.

Sh-2 (No. 548): black shale from the Permian Maizuru Group in Ichinomiya-cho, Hyogo Prefecture, Southwest Japan. The clay minerals occurring in this shale are chlorite and illite.

Sh-3 (No. 264-1): black shale from the Upper Páleozoic strata in Bisei-cho, Okayama Prefecture, Southwest Japan. 
Table 1. Chemical analyses of shale samples

\begin{tabular}{|c|c|c|c|c|}
\hline & Sh-1* & Sh-2** & Sh-3* & $\mathrm{Sh}-4^{*}$ \\
\hline $\mathrm{SiO}_{2}$ & 61.95 & 58.42 & 68.78 & 60.64 \\
\hline $\mathrm{TiO}_{2}$ & 0.67 & 0.66 & 0.53 & 0.82 \\
\hline $\mathrm{Al}_{2} \mathrm{O}_{3}$ & 19.57 & 17.06 & 15.41 & 17.95 \\
\hline $\mathrm{Fe}_{2} \mathrm{O}_{3}$ & 1.27 & 2.27 & 1.18 & 2.17 \\
\hline $\mathrm{FeO}$ & 3.54 & 3.88 & 2.81 & 4.22 \\
\hline $\mathrm{MnO}$ & 0.18 & 0.05 & 0.06 & 0.04 \\
\hline $\mathrm{MgO}$ & 2.41 & 3.31 & 1.61 & 2.68 \\
\hline $\mathrm{CaO}$ & 0.53 & 2.26 & 0.69 & 0.83 \\
\hline $\mathrm{Na}_{2} \mathrm{O}$ & 2.33 & 2.76 & 1.47 & 2.65 \\
\hline $\mathrm{K}_{2} \mathrm{O}$ & 4.44 & 2.99 & 3.32 & 2.84 \\
\hline $\mathrm{P}_{2} \mathrm{O}_{5}$ & 0.14 & 0.13 & 0.10 & 0.15 \\
\hline Ig. loss & 3.44 & 5.86 & 3.37 & 5.74 \\
\hline Total & 100.47 & 99.65 & 99.33 & 100.73 \\
\hline
\end{tabular}

Sh-4 (No. 319): black shale from the Permian Tsunemori Group in Mine-shi, Yamaguchi Prefecture, Southwest Japan.

Chemical analyses of these shale samples are presented in Table 1.

Akiyoshi limestone: limestone from the Akiyoshi Limestone Group (Paleozoic) in Mine-shi, Yamaguchi Prefecture, Southwest Japan, containing 20 30ppm Mn.

Synthetic calcite: calcite prepared by the gelgrown technique (HENISCH, 1970), containing $<100$ ppm Mn.

Ch-1: chlorite from Sanwa-cho, Nagasaki Prefecture, Southwest Japan, containing 14.00\% $\mathrm{Fe}_{2} \mathrm{O}_{3}, 0.30 \% \mathrm{MnO}, 23.23 \% \mathrm{MgO}$ and $1.57 \%$ $\mathrm{CaO}$. Principal impurity is quartz.

Mu-1: muscovite from Ishikawa-cho, Fukushima Prefecture, Northeast Japan, containing $3.87 \% \mathrm{Fe}_{2} \mathrm{O}_{3}, 0.04 \% \mathrm{MnO}$ and $0.28 \% \mathrm{MgO}$.

$\mathrm{Hm}-1$ : hematite from Waga-cho, Iwate Prefecture, Northeast Japan, containing 95.10\% $\mathrm{Fe}_{2} \mathrm{O}_{3}, 0.02 \% \mathrm{MnO}$ and $0.25 \% \mathrm{MgO}$.

$\mathrm{Mg}$-1: magnetite from Kawakami-gun, Okayama Prefecture, Southwest Japan, contaning 95.71\% $\mathrm{Fe}_{2} \mathrm{O}_{3}, 0.24 \% \mathrm{MnO}, 0.40 \% \mathrm{MgO}$ and $0.71 \% \mathrm{CaO}$.

\section{EXPERIMENTAL}

Leaching experiments To $0.2 \mathrm{~g}$ of powdered sample taken in a beaker, $20 \mathrm{ml}$ of leachent was added and the suspension was allowed to stand for $1 \mathrm{~h}$ with occasional stirring. In the case of hot leachent, $0.2 \mathrm{~g}$ of powdered sample was weighed into a test tube, $20 \mathrm{ml}$ of leachent was added and the suspension was heated in boiling water for $1 \mathrm{~h}$ with occasional stirring. The whole of the suspension was put into a measuring flask and the volume was adjusted to $100 \mathrm{ml}$ with water. After centrifugation, the supernatant solution was put into a bottle and used for the determination of the leached elements. The residue was washed five times with water, airdried and stored for further experiments. The leachents used were $0.5 \mathrm{M}$ acetic acid, $0.1,1,2$ and $6 \mathrm{M}$ hydrochloric acid solutions. The determination of iron, magnesium and manganese was carried out by atomic absorption spectroscopy using a Nippon Jarrel-Ash Model AA781 and a Hitachi Model 518 Atomic Absorption Spectrometer.

Treatments with $0.5 M$ acetic acid and $2 M$ hydrochloric acid The sample was treated by the method described above.

Treatment with 1:1 (v/v) sulfuric acid To $0.2 \mathrm{~g}$ of powdered sample taken in a platinum crucible, $3 \mathrm{ml}$ of $1: 1(\mathrm{v} / \mathrm{v})$ sulfuric acid was added and the mixture was heated to dryness on a hot plate.

Treatment with $30 \%$ hydrogen peroxide Powdered sample $(0.2 \mathrm{~g})$ was heated in $30 \%$ hydrogen peroxide solution on a water bath at $85^{\circ} \mathrm{C}$ for $3 \mathrm{~h}$ with occasional addition of the solution. After centrifugation, the residue was washed five times with water and air-dried at room temperature.

Treatment with hydrofluoric acid To $0.5 \mathrm{~g}$ of powdered sample taken in a platinum crucible, $3 \mathrm{ml}$ of $1: 1(\mathrm{v} / \mathrm{v})$ hydrochloric acid and $10 \mathrm{ml}$ of $47 \%$ hydrofluoric acid were added and the mixture was evaporated to dryness on a hot plate. The residue was dissolved in $1 \mathrm{M}$ hydrochloric acid. The insoluble residue was centrifuged, washed five times with water and airdried at room temperature.

Heat treatment Powdered sample $(0.2 \mathrm{~g})$ was ignited in a platinum crucible for $30 \mathrm{~min}$.

Samples after these treatments were used for ESR measurements. All chemicals used were 
of special grade (Wako Pure Chemicals).

ESR measurements Finely ground sample was put into an ESR quartz tube of several millimeters' diameter and X-band spectra were recorded at room temperature on a JEOL JES ME-3X Spectrometer $(100 \mathrm{kHz}$ field modulation), scanning over field range of $86-586 \mathrm{mT}$ with response time of $0.1 \mathrm{sec}$ and sweep time of $10 \mathrm{~min}$. Other measuring conditions are given in figure captions. $g$-Values were determined relative to DPPH $\left(g_{\text {eff }}=2.0036\right)$.

$X$-ray analysis $\mathrm{X}$-ray analysis was carried out using the random powder method on a

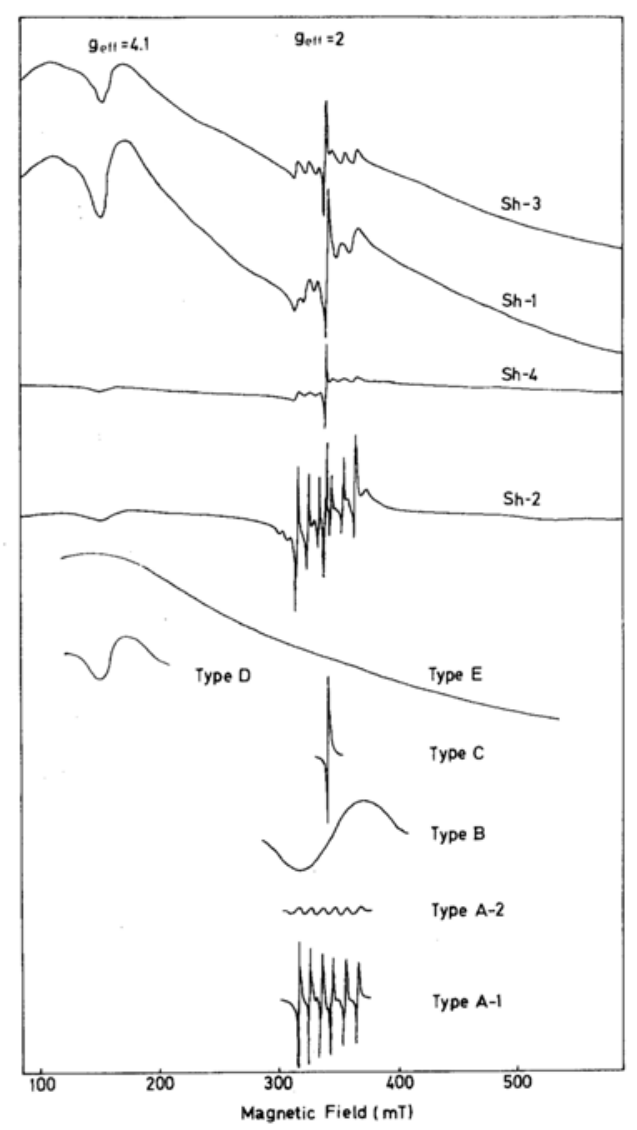

Fig. 1. ESR spectra of some shale samples.

Measuring conditions: Sh-1; power $25.6 \mathrm{~mW}$, crystal current $0.70 \mathrm{~mA}$, mod. width $2 \mathrm{mT}$, gain $7.1 \times 10$, Sh-2; power $25.6 \mathrm{~mW}$, crystal current $0.50 \mathrm{~mA}$, mod. width $2 \mathrm{mT}$, gain $1.6 \times 10, \mathrm{Sh}-3$; power $25.6 \mathrm{~mW}$, crystal current $0.70 \mathrm{~mA}$, mod. width $2 \mathrm{mT}$, gain $4.0 \times 10, \mathrm{Sh}-4$; power $20 \mathrm{~mW}$, crystal current $0.50 \mathrm{~mA}$, mod. width 2 $m T$, gain $5.0 \times 1$.
Toshimba X-ray Diffractometer.

\section{RESULTS ANS DisCUSSION}

ESR spectra of shales Figure 1 shows ESR spectra for several shale samples. The shales exhibit spectra consisting of four or five types of resonances; type A: multiplet resonance which is composed of six lines near $g_{\text {eff }}=2$ at intervals of about $9 \mathrm{mT}$, type B: broad resonance centered near $g_{\text {eff }}=2$, type C: sharp intense resonance close to $g_{\text {eff }}=2$, type D: resonance near $g_{\text {eff }}=4.1$, and type E: right inclined resonance covering a wide magnetic field.

Type $A \quad$ This type of resonance is divided into two groups on the basis of its line shape; one gives six sharp lines (type A-1) and another shows six lines which is not sharp compared with those of type A-1 (type A-2).

Type A-1 Funwara (1964) showed that randomly distributed trace $\mathrm{Mn}(\mathrm{II})$ in calcium carbonate (limestone) gave a resonance with hyperfine structure. Our experiments also show that trace amounts of $\mathrm{Mn}$ (II) indicate sharp hyperfine lines both in naturally occurring limestones and synthetic calcite (Fig. 2). The resonance in shale Sh-2 can, therefore, be interpreted as due to $\mathrm{Mn}$ (II) randomly distributed in calcite occurring in the shale. The occurrence of calcite in this shale was confirmed by X-ray analysis and microscopic examination.

Type A-2 Type A-2 resonance gives characteristic hyperfine structure of $\mathrm{Mn}$ (II), although six lines are relatively broad compared with those of type A-1 resonance. Figure 3 shows the ESR spectra of shales Sh-1 and Sh-2 prior to and after the treatments with $0.5 \mathrm{M}$ acetic acid and $2 \mathrm{M}$ hydrochloric acid. While type A-1 resonance in untreated shale $\mathrm{Sh}-2$ disappeared after treatments with these acid solutions, type A-2 resonance remained after the same treatments. Type A-2 resonance can be attributed to $\mathrm{Mn}$ (II) which is randomly distributed in clay minerals. This will be discussed later.

Type $B \quad$ A very broad resonance $\left(\Delta \mathrm{H}_{\mathrm{pp}} \lesssim\right.$ $150 \mathrm{mT}$ ) centered near $g_{\text {eff }}=2$ in glass samples has tended to be due mainly to exchange cou- 
pled Fe(III) ions (GRISCOM, 1980). On the other hand, $\mathrm{Fe}$ (III) ions in tetrahedral and octahedral coordinations display a considerably broad resonance with $g_{\text {eff }}=2$. Many unanswered questions remain regarding the structure of the magnetic phases giving rise to this type of resonance. Nevertheless, the broad $g_{\text {eff }}=2$ resonance overlapped with the hyperfine lines of $\mathrm{Mn}(\mathrm{II})$ in the spectra of shales may be attributed to $\mathrm{Fe}(\mathrm{III})$ ions.

Type $C \quad$ In all shale samples, a sharp resonance line was observed near $g_{\text {eff }}=2$. A similar resonance has been found to appear in the spectra of natural carbonaceous materials (UEBERSFELD et al., 1954; DUCHESNE et al., 1961; HALl et al., 1974; Sidwell et al., 1979), such as coals, peats, lignites and oil shales, and occasionally limestones (WATANABE et al., 1967). WATANABE et al. (1967) suggested that type C resonance in Akasaka limestones was attributed to the aggregates of condensed polycyclic aromatic compounds (amorphous carbon) which had $\pi$ electron radicals produced during the diagenesis by decomposition of organic substances. Type $\mathrm{C}$ resonance in shales remained on treating with hydrofluoric acid but disappeared after treatment with sulfuric acid and heat treat-

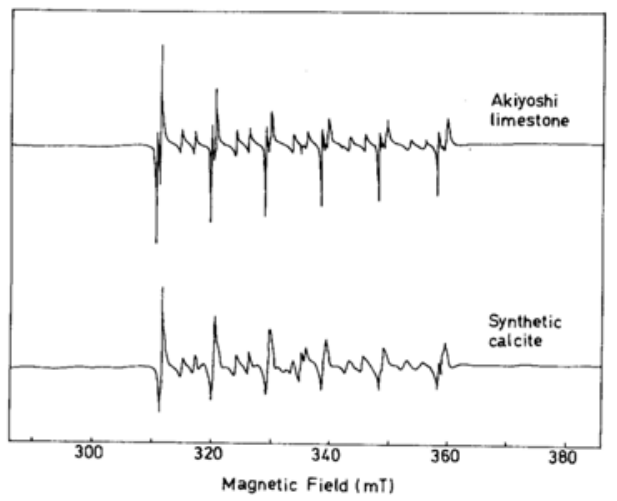

Fig. 2. ESR spectra of Akiyoshi limestone and synthetic calcite containing $\mathrm{Mn}(I I)$.

Measuring conditions: Akiyoshi limestone; power 12.8 $\mathrm{mW}$, crystal current $0.50 \mathrm{~mA}, \mathrm{mod}$. width $0.05 \mathrm{mT}$, gain $3.2 \times 10$, synthetic calcite; power $20 \mathrm{~mW}$, crystal current $0.60 \mathrm{~mA}$, mod. width $0.4 \mathrm{mT}$, gain $2.0 \times 10$.

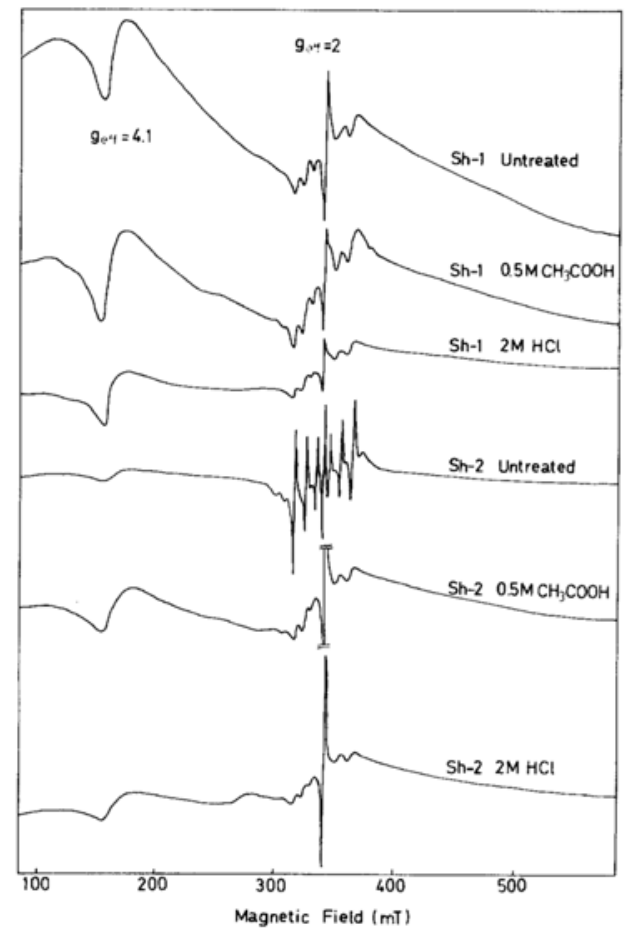

Fig. 3. ESR spectra of shales Sh-1 and Sh-2 prior to and after the chemical treatments.

Measuring conditions: power $25.6 \mathrm{~mW}$, mod. width 2 $m T$, Sh-1 Untreated; crystal current $0.70 \mathrm{~mA}$, gain $7.1 \times$ 10, Sh-1 0.5 $\mathrm{M} \mathrm{CH}_{3} \mathrm{COOH}$; crystal current $0.70 \mathrm{~mA}$, gain $6.3 \times 10, S h-12 \mathrm{M} \mathrm{HCl}$; crystal current $0.60 \mathrm{~mA}$, gain $5.0 \times 10$, Sh-2 Untreated; crystal current $0.50 \mathrm{~mA}$, gain $1.6 \times 10, \mathrm{Sh}-20.5 \mathrm{M} \mathrm{CH}_{3} \mathrm{COOH}$; crystal current 0.70 $m A$, gain $3.6 \times 10, S h-22 \mathrm{M} \mathrm{HCl}$; crystal current 0.70 $m A$, gain $3.6 \times 10$.

ment. One of the possible origins of type $\mathrm{C}$ resonance is organic free radicals in carbonaceous materials. The radicals are moderately stable, because the resonance did not disappear on treating with $30 \%$ hydrogen peroxide solution.

Type $D \quad$ All of the shale samples exhibited this type of resonance, though the variations of the signal intensities occurred. A similar resonance was recognized in some clays and clay minerals (HALL et al., 1974; MEADS and MALDEN, 1975; ANGEL and VinCENT, 1978), micas (KeMP, 1971, 1972) and organic materials containing Fe(III) (WICKMAN et al., 1965; CHESHIRE et al., 1977; SENESI et al., 1977). The theory of the 
resonance in the $g_{\text {eff }}=4$ region has been discussed by various investigators (GRIFFITH, 1964; HoluJ, 1966; Blumberg, 1967; Dowsing and GIBSON, 1969; SENESI et al., 1977). It has been shown that this type of resonance arises from $\mathrm{Fe}$ (III) ions occupying sites of orthorhombic symmetry with high distortion parameters $\lambda=$ $E / D(\lambda=1 / 3)$ and $D$. According to our experiments, the $g_{\text {eff }}=4.1$ resonance was not detected in iron oxide minerals such as hematite and magnetite (Fig. 4), but observed in chlorite $\mathrm{Ch}-1$ and muscovite Mu-1 (Fig. 5). Considering the results of the present and previous studies, it is probable that type $\mathrm{D}$ resonance is attributed to $\mathrm{Fe}$ (III) which is associated with clay minerals occurring in shales.

Type $E \quad$ In the spectra of shales Sh-1 and Sh-3, a remarkably inclined resonance covering a wide magnetic field was observed (Fig. 1). This resonance has some resemblance to that of hematite Hm-1 (Fig. 4). The ESR spectrum of magnetite $\mathrm{Mg}-1$ (Fig. 4) draws an arc over a wide field. Thus, some inclusion of hematite must be regarded in the case of such an inclined spectral pattern as in shales Sh-1 and Sh-3. This resonance diminished after treatment with $0.5 \mathrm{M}$ acetic acid and disappeared on treating with $2 \mathrm{M}$ hydrochloric acid (Fig. 3).

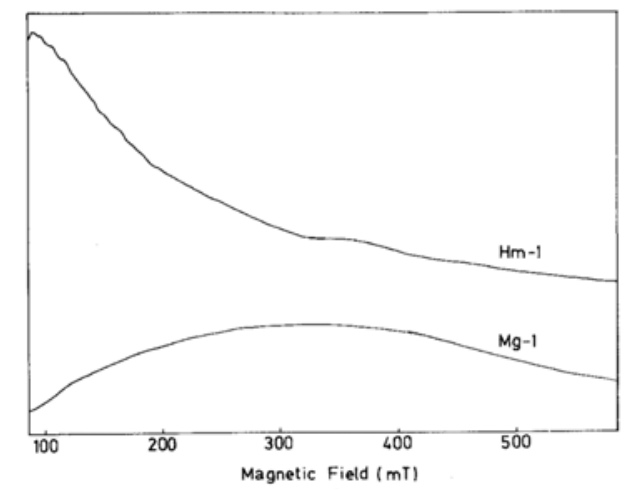

Fig. 4. ESR spectra of hematite Hm-1 and magnetite $\mathrm{Mg}-1$.

Measuring conditions: $\mathrm{Hm}-1$; power $25.6 \mathrm{~mW}$, crystal current $0.70 \sim 0.73 \mathrm{~mA}$, mod. width $0.2 \mathrm{mT}$, gain $3.6 \times$ $1, \mathrm{Mg}-1$; power $10 \mathrm{~mW}$, crystal current $0.05 \sim 0.35 \mathrm{~mA}$, mod. width $2 \mathrm{mT}$, gain $2.0 \times 1$.
Distribution of $\mathrm{Mn}(I I)$ and $\mathrm{Fe}(I I I)$ in shales Above-mentioned results afford useful information on the distribution and states of elements in shales. For this purpose, leaching experiments were also employed.

Leaching experiments of shales Leaching experiments show that there is a clear linear correlation between $\mathrm{MgO}$ and $\mathrm{Fe}_{2} \mathrm{O}_{3}$ which are dissolved from a shale on treating with various acid solutions and, moreover, the straight line intersects the origin (Fig. 6). This result indicates that the amount of the elements leached from a shale increases not stepwise but gradually with leaching ability of the leachents. In general, shale is composed mainly of quartz, feldspars and clay minerals with some minor components such as carbonates, iron oxide minerals, apatite, organic materials, etc. Taking into account the mineral composition of shale, we consider that iron and magnesium are incorporated

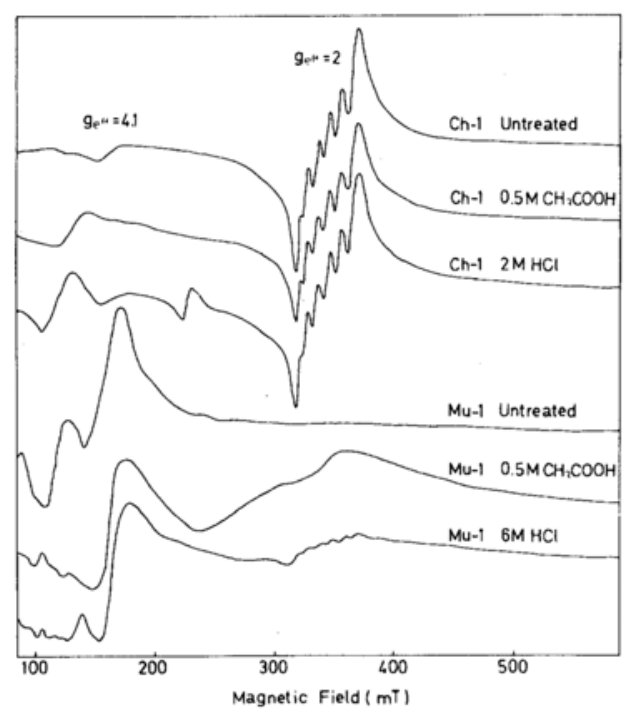

Fig. 5. ESR spectra of chlorite Ch-1 and muscovite Mu1 prior to and after the chemical treatments.

Measuring conditions: power $25.6 \mathrm{~mW}$, crystal current $0.70 \mathrm{~mA}, \mathrm{Ch}-1$ Untreated; mod. width $0.4 \mathrm{mT}$, gain $5.6 \times$ 10, Ch-1 0.5 $\mathrm{M} \mathrm{CH}_{3} \mathrm{COOH}$; mod. width $0.4 \mathrm{mT}$, gain 7.9 $\times 10, \mathrm{Ch}-12 \mathrm{M} \mathrm{HCl}$; mod. width $0.4 \mathrm{mT}$, gain $7.1 \times 10$, Mu-1 Untreated; mod. width $2 \mathrm{mT}$, gain $1.6 \times 10, \mathrm{Mu}-1$ $0.5 \mathrm{M} \mathrm{CH}{ }_{3} \mathrm{COOH} ;$ mod. width $0.4 \mathrm{mT}$, gain $7.1 \times 10$, $\mathrm{Mu}-1 \mathrm{KM} \mathrm{HCl} ;$ mod. width $0.4 \mathrm{mT}$, gain $7.1 \times 10$. 


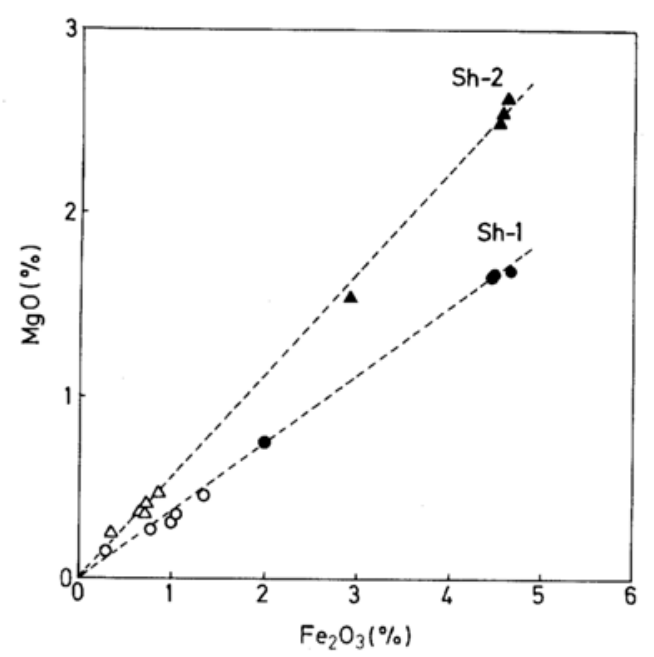

Fig. 6. Relationship between iron and magnesium leached from shales Sh-1 and Sh-2 by the chemical treatments.

o, $\triangle$ : $0.5 \mathrm{M} \mathrm{CH}_{3} \mathrm{COOH}, 0.1,1,2$ and $6 \mathrm{M} \mathrm{HCl}$ solutions.

$\bullet, \mathbf{A}: \quad 0.1,1,2$ and $6 \mathrm{M} \mathrm{HCl}$ solutions (heated).

The amounts of the elements are shown as oxides in terms of per cent to the whole rock.

mainly in clay minerals. If these elements are present in other forms such as soluble salts and oxides, they might either be dissolved completely on treating with an acid solution of certain concentration or would differ from each other in the rate and degree of dissolution. In the latter case, linear relation as seen in Fig. 6 would not exist.

Type A-1 resonance Manganese was leached linearly with iron and magnesium from a shale on treating with various acid solutions (Figs. 7 and 8). This result suggests that some part of the manganese is incorporated in clay minerals together with iron and magnesium. This view is supported by the ESR spectra of some clay minerals (Fig. 5). As X-ray analysis indicated the presence of chlorite and illite in the shales, the experiments were made on chlorite $\mathrm{Ch}-1$ and muscovite Mu-1. The latter was used instead of illite, because pure illite was not obtained. The ESR spectra of these minerals are not substantially different from those of untreated shale Sh-1 and acid treated shale Sh-2,

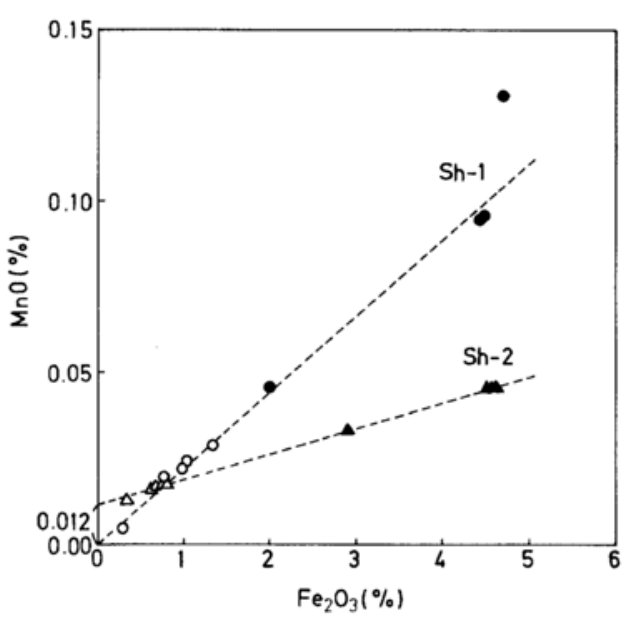

Fig. 7. Relationship between iron and manganese leached from shales Sh-1 and Sh-2 by the chemical treatments. Symbols and note are the same as those in Fig. 6.

except for a difference in the signal intensity of the resonances and the lack of type $\mathrm{C}$ resonance. From the above results, it is concluded that hyperfine lines with comparatively broad line width (type A-2) arise from $\mathrm{Mn}(\mathrm{II})$ in clay minerals.

Distribution of $M n(I I) \quad$ The hyperfine lines of $\mathrm{Mn}$ (II) occur because of interaction between

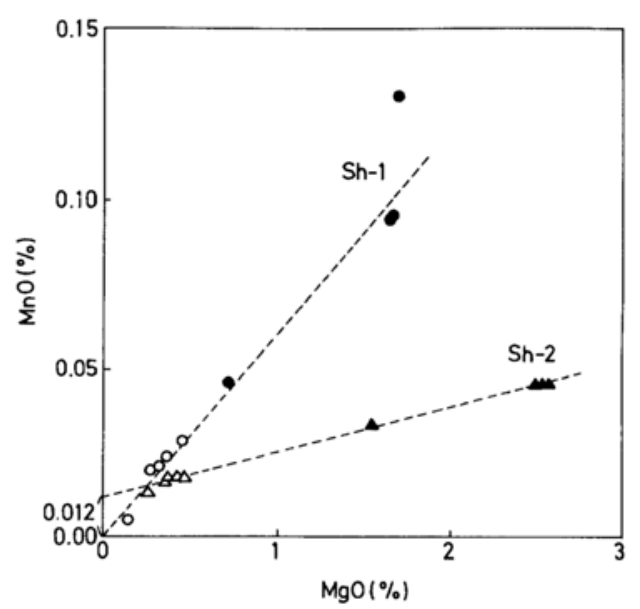

Fig. 8. Relationship between magnesium and manganese leached from shales Sh-1 and Sh-2 by the chemical treatments. Symbols and note are the same as those in Fig. 6. 
the unpaired electrons and the nuclear spin $(I=$ $5 / 2$ ) of ${ }^{55} \mathrm{Mn}$. FuJwara (1964) suggested that the states of $\mathrm{Mn}$ (II) which exhibited hyperfine structure were defined as free ions. In manganese carbonate, the hyperfine structure is smeared out on a spectrum of very broad line width (Funtwara, 1964). According to our experiments, manganese minerals (e.g. rhodochrosite) also gave no hyperfine lines of $\mathrm{Mn}$ (II) in the spectrum.

Manganese which exhibits type A-2 resonance is not present as clusters, i.e. manganese minerals, but as isolated ions in the clay minerals. According to its ionic radius, $\mathrm{Mn}$ (II) ion probably replaces $\mathrm{Mg}$ (II) and $\mathrm{Fe}$ (II) ions in the clay minerals.

In shale Sh-1 which gives type A-2 resonance, manganese is bound to clay minerals. In shale Sh- 2 which exhibits type A-1 resonance in untreated sample and type A-2 resonance after acid treatments, manganese is present both in calcite and clay minerals. The intercept of the straight line for shale Sh-2 in Figs. 7 and 8 represents the amount of manganese distributed in calcite $(0.012 \% \mathrm{MnO})$. The difference in manganese content between the whole rock and calcite gives the amount of manganese distributed in clay minerals. As the $\mathrm{MnO}$ content of the whole rock is $0.05 \%$ (Table 1 ), the amount of manganese bound to clay minerals is estimated to be $0.038 \% \mathrm{MnO}$.

Distribution of $\mathrm{Fe}(\mathrm{III}) \quad$ Leaching experiments show that most of the iron is associated with clay minerals, and as shales give type D resonance, a part of the iron in clay minerals is present as $\mathrm{Fe}(\mathrm{III})$ occupying sites of orthorhombic symmetry. Type B resonance suggests the presence of $\mathrm{Fe}$ (III) in tetrahedral and octahedral coordinations, but at present it is not possible to go further in identifying the site of $\mathrm{Fe}(\mathrm{III})$. In shales which show type $\mathrm{E}$ resonance, some part of the iron is present as hematite.

\section{REFERENCES}

ANGEL, B. R. and HALL, P. L. (1973) Electron spin resonance studies of kaolins. Proc. Int. Clay Conf.
Madrid, 47-60.

ANGEL, B. R. and VINCENT, W. E. J. (1978) Electron spin resonance studies of iron oxides associated with the surface of kaolins. Clays Clay Minerals 26, 263272.

BLUMBERG, W. E. (1967) The EPR of high spin $\mathrm{Fe}^{3+}$ in rhombic field. In: Magnetic resonance in biological systems (ed. EHRENBERG, A., MALSTRÖM, B. E. and VÄNnGÅRT, T.). Pergamon Press, London, 119-133.

Cheshire, M. V., Berrow, M. L., Goodman, B. A. and Mundie, C. M. (1977) Metal distribution and nature of some $\mathrm{Cu}, \mathrm{Mn}$ and $\mathrm{V}$ complexes in humic and fluvic acid fractions of soil organic matter. Geochim. Cosmochim. Acta 41, 1131-1138.

Dowsing, R. D. and GIBSON, J. F. (1969) Electron spin resonance of high-spin $d^{5}$ systems. J. Chem. Phys. 50, 294-303.

DUCHESNE, J., DEPIREUX, J. and VAN DER KAA, J. M. (1961) Origin of free radicals in carbonaceous rocks. Geochim. Cosmochim. Acta 23, 209-218.

FUJIWARA, S. (1964) Investigation of trace impurities in solids by electron paramagnetic resonance. Distribution of manganese in calcium carbonate. Anal. Chem. 36, 2259-2261.

GHOSE, S. and TSANG, T. (1973) Structural dependence of quadrupole coupling constant $\mathrm{e}^{2} \mathrm{qQ} / \mathrm{h}$ for ${ }^{27} \mathrm{Al}$ and crystal field parameter $\mathrm{D}$ for $\mathrm{Fe}^{3+}$ in aluminosilicates. Am. Mineral. 58, 748-755.

GRIFFITH, J. S. (1964) Theory of the isotropic $g$ value of 4.27 found for some high-spin ferric ions. Mol. Phys. 8, 213-216.

GRISCOM, D. L. (1980) Electron spin resonance in glasses. J. Non-Cryst. Solids 40, 211-272.

Hall, P. L., ANGel, B. R. and Braven, J. (1974) Electron spin resonance and related studies of lignite and ball clay from South Devon, England. Chem. Geol. 13, 97-113.

HENISCH, H. K. (1970) Crystal growth in gels. The Pennsylvania State University Press.

HoluJ, F. (1966) The spin Hamiltonian and intensities of the ESR spectra originating from large zerofield effects on ${ }^{6} S$ states. Can. J. Phys. 44, 503-508.

INAZUMI, A. (1975) Chemical composition of Paleozoic pelitic rocks in Chugoku, Southwest Japan. $J$. Geol. Soc. Japan 81, 513-520. (in Japanese with English abstract)

KEMP, R. C. (1971) Orthorhombic iron centres in muscovite and phlogopite micas. J. Phys. C: Solid State Phys. 4, L11-L13.

KEMP, R. C. (1972) Electron spin resonance of $\mathrm{Fe}^{3+}$ in phlogopite. J. Phys. C: Solid State Phys. 5, 3566-3572.

MEADS, R. E. and MALDEN, P. J. (1975) Electron spin resonance in natural kaolinites containing $\mathrm{Fe}^{3+}$ 
and other transition metal ions. Clay Minerals 10, 313-345.

Senesi, N., Griffith, S. M., SChNitzer, M. and TOWNSEND, M. G. (1977) Binding of $\mathrm{Fe}^{3+}$ by humic materials. Geochim. Cosmochim. Acta 41, 969-976.

Sidwell, B. L., MCKinney, L. E., Bozeman, M. F., EgBujoR, P. C. and EATON, G. R. (1979) Electron paramagnetic resonance studies of oil shale, shale oil, and spent shale. Geochim. Cosmochim. Acta 43, 1337-1342.
JEBERSFELD, J., ÉTIENNE, A. and COMBRISSON, J. (1954) Paramagnetic resonance, a new property of coal-like materials. Nature 174, 614 .

Watanabe, M., ABE, S. and Fujiwara, S. (1967) Study of carbonaceous materials in Akasaka limestones. Chikyukagaku (Geochemistry) 1, 1-6. (in Japanese with English abstract)

Wickman, H. H., Klein, M. P. and Shirley, D. A. (1965) Paramagnetic resonance of $\mathrm{Fe}^{3+}$ in polycrystalline ferrichrome A. J. Chem. Phys. 42, 21132117. 